\title{
Correspondence
}

\section{Ultrasound guidance and success rates of axillary brachial plexus block - I}

To the Editor, We read with great interest the recently reported study of Chan et al. ${ }^{1}$ This study warrants comment due to the low success rates reported after axillary brachial plexus block, despite the authors' internationally recognized experience with these techniques. The study compared regional anesthesia of the upper limb using an ultrasound-guided (US) approach (the most expensive technique) or a combined nerve stimulator (NS) ultrasound-guided (USNS) approach (the most sophisticated technique) to NS alone. The authors reported 30 -min post-block success rates of $62.9 \%$, $80.7 \%$ and $82.8 \%$ for NS, USNS and US techniques, respectively. These success rates are considerably lower than those reported after brachial plexus block using a transarterial technique, which is no longer recommended. Stan et al. ${ }^{2}$ reported a success rate of $88.8 \%$ and a low rate of complications $(<1 \%)$ in 1,000 consecutive patients undergoing a transarterial approach to brachial plexus block.

Several methodological issues may explain the results observed by Chan et al. First, proximal triceps response is not always an adequate endpoint to assess radial response, since direct muscle contraction may be easily confused with direct nerve stimulation. This point is highlighted by the pivotal role played by successful radial nerve block not only for axillary brachial block, ${ }^{3}$ but also for infraclavicular blocks ${ }^{4}$ and interscalene blocks (unpublished data). Second, their selection of a minimum current value less than 0.5 $\mathrm{mA}$, is somewhat vague. Neuburger et al. ${ }^{5}$ have shown that thresholds down to $0.3 \mathrm{~mA}$ at a pulse width of $100 \mu \mathrm{sec}$ are required to achieve a success rate of 95\% in patients without polyneuropathy. Moreover, Eifert et al. ${ }^{6}$ demonstrated a correlation between stimulation thresholds and axillary block success rate. Their observed failure rate was $10.7 \%$ when the stimulation threshold was $0.6 \mathrm{~mA}$. With a stimulation amplitude of $0.4 \mathrm{~mA}$, no failures occurred. The reported threshold range $(0.28 \mathrm{~mA}$ to $0.5 \mathrm{~mA})$ in Chan et al.'s study was quite large between groups, which confounds assessment of success rates and complication frequencies. The patient drop-out rate $(14.5 \%)$ in their study was also quite high, which may have contributed to a beta-type error.

Finally, the infraclavicular approach ${ }^{7}$ was shown to have a very high success rate and a low incidence of complications with one stimulation and injection. Under these conditions, is the infraclavicular approach not a better technique for hand surgery?

\section{José Aguirre MD}

Stephan Blumenthal MD

Alain Borgeat MD PhD

Balgrist University Hospital, Zurich, Switzerland

The authors are not supported by, nor maintain any financial interest in, any commercial activity that may be associated with the topic of this article.

E-mail alain.borgeat@balgrist.ch

Accepted for publication April 16, 2007.

\section{References}

1 Chan VW, Perlas A, McCartney CJ, Brull R, Xu D, Abbas $S$. Ultrasound guidance improves success rate of axillary brachial plexus block. Can J Anesth 2007; 54: 176-82.

2 Stan TC, Krantz MA, Solomon DL, Poulos JG, Chaouki $K$. The incidence of neurovascular complications following axillary brachial plexus block using a transarterial approach. A prospective study of 1,000 consecutive patients. Reg Anesth 1995; 20: 486-92.

3 Niesel HC, van Aken H. Lokalanästhesie, Regionalanästhesie, Regionale Schmerztherapie. Thieme Verlag, 2. Auflage 2003: 285-6.

4 Deleuze A, Gentili ME, Marret E, Lamonerie L, Bonnet $F$. A comparation of a single-stimulation lateral infraclavicular plexus block with a triple-stimulation axillary block. Reg Anesth Pain Med 2003; 28: 89-94.

5 Neuburger M, Rotzinger M, Kaiser $H$. Electric nerve stimulation in relation to impulse strength. A qualitative study of the distance of the electrode point to the nerve (German). Anaesthesist 2001; 50: 181-6.

6 Eifert B, Hahnel J, Kustermann J. Axillary blockade of the brachial plexus. A prospective study of blockade success using electric nerve stimulation (German). Anaesthesist 1994; 43: 780-5.

7 Borgeat A, Ekatodramis G, Dumont C. An evaluation of the infraclavicular block via a modified approach of the Raj technique. Anesth Analg 2001; 93: 436-41. 